\title{
SILAGENS DE FORRAGEIRAS TROPICAIS ADAPTADAS ÀS CONDIÇÕES DO SEMIÁRIDO
}

\author{
CORDEIRO, Matheus Wilson Silva ${ }^{1}$ \\ ROCHA JÚNIOR, Vicente Ribeiro ${ }^{2}$ \\ MONÇÃ̃o, Flávio Pinto ${ }^{3}$ \\ CORDEIRO, André Felipe Silva ${ }^{4}$
}

\begin{abstract}
\begin{tabular}{lll}
\hline Recebido em: 2019.12 .12 & Aprovado em: 2021.02 .08 & ISSUE DOI: $10.3738 / 21751463.3726$
\end{tabular}
RESUMO: As condições climáticas de regiões semiáridas no mundo impõem desafios para a produção de alimentos para os ruminantes. Baixos índices pluviométricos com distribuição desuniforme dificultam o estabelecimento de grande parte das culturas agrícolas tradicionais. Desta forma, a busca por cultivares forrageiros que melhor se adaptem com maiores produções de matéria seca por hectare, e que apresentem características permitindo sua conservação, como pelo processo de ensilagem são de grande relevância para essas regiões. O objetivo dessa revisão de literatura foi discorrer sobre características de forrageiras tropicais adaptadas às condições do semiárido e a aplicabilidade de sua utilização na forma de silagem. O sorgo biomassa, o BRS capiaçu e a palma forrageira possuem alto potencial de produção por hectare além de apresentarem características que permitam sua ensilagem. Os desafios impostos à produção de ruminantes pelo clima das regiões semiáridas do mundo podem ser contornados com a escolha de forragens que consigam produzir e ser conservadas nessas condições.
\end{abstract}

Palavras-chave: Sorgo Biomassa. BRS Capiaçu. Palma Forrageira. Ensilagem.

\section{TROPICAL FORAGE SILAGE ADAPTED TO SEMIARID CONDITIONS}

SUMMARY: Climatic conditions in semiarid regions of the world pose challenges for ruminant food production. Low rainfall rates with uneven distribution make it difficult to establish much of traditional agricultural crops. Thus, the search for forage cultivars that best adapt with higher yields of dry matter per hectare, and that have characteristics allowing their conservation, as by the ensiling process are of great relevance to these regions. The aim of this literature review was to discuss the characteristics of tropical forages adapted to semiarid conditions and the applicability of their use as silage. Biomass sorghum, BRS capiaçu and forage palm have high yield potential per hectare and have characteristics that allow its ensiling. The climate challenges of ruminant production in the semiarid regions of the world can be overcome by choosing which fodder to produce and conserving under these conditions.

Keywords: Sorghum Biomass. BRS Capiaçu. Forage Palm. Silage.

\section{INTRODUÇÃO}

A região semiárida do Brasil ocupa área de $1.128 .697 \mathrm{~km}^{2}$, abrangendo 1.262 municípios dos estados de Alagoas, Bahia, Ceará, Maranhão, Minas Gerais, Paraíba, Pernambuco, Piauí, Rio Grande do Norte e Sergipe (BRASIL, 2017). A região tem como característica a incidência baixa de chuvas com até $800 \mathrm{~mm}$ por ano (ARAÚJO, 2015). Aliado a este fato, a precipitação tem distribuição irregular sendo frequente a ocorrência de dias sem chuva mesmo no verão (CORREIA et al., 2011).

\footnotetext{
${ }^{1}$ Discente do Programa de Pós-Graduação em Zootecnia da Universidade Estadual de Montes Claros - Unimontes.

${ }^{2}$ Professor do Departamento de Ciências Agrárias, Universidade Estadual de Montes Claros

${ }^{3}$ Pós-Doutorando, Prof. Colaborador, Universidade Estadual de Montes Claros, UNIMONTES

${ }^{4}$ Acadêmico do Curso de Zootecnia da Universidade Estadual de Montes Claros - Unimontes
} 
O semiárido brasileiro tem a produção animal como uma das atividades de maior importância socioeconômica, com destaque para a criação de ruminantes (SANTOS et al., 2011). Sistemas produtivos com estes animais utilizam, principalmente, de pasto como fonte de alimento. Neste contexto, a produção do aporte forrageiro para alimentação dos animais deve ser realizada no período de maior disponibilidade de chuvas. A produção de animais em pasto deve focar na maior eficiência, entretanto, a sazonalidade produtiva de forrageiras tropicais prejudica o desenvolvimento dos animais (SAMPAIO et al., 2017). Fatores climáticos são componentes incontroláveis dentro do sistema produtivo, sendo seus efeitos mais intensos quando se trabalha com ruminantes em pasto, que é escasso cerca de 4 a 6 meses do ano (DANIEL et al., 2019). Uma alternativa aplicável a esta situação, a fim de se lidar com estes déficits sazonais de disponibilidade de alimentos, é a conservação do excedente forrageiro, sendo a técnica de ensilagem a mais usual (WILKINSON; RINNE, 2017).

Ao se ter consciência das condições ambientais locais se torna possível à escolha de culturas com potencial de utilização para se ensilar, que sejam produtivas e que sua silagem seja de qualidade (MÂCEDO et al., 2019). Em sistemas pecuários no semiárido é estratégico a otimização da produtividade das culturas forrageiras, principalmente no que se diz respeito na melhoria no uso da água.

Diante do que foi dito, o objetivo dessa revisão de literatura foi discorrer sobre características de forrageiras tropicais adaptadas às condições do semiárido e a aplicabilidade de sua utilização na forma de silagem.

\section{PROCESSO DE ENSILAGEM}

A ensilagem é um procedimento que visa preservar o alimento em um ambiente anaeróbico, tendo como produto a silagem que passa por alterações físico-químicas e sensoriais em decorrência da fermentação de microrganismos (MUCK, 1988; TOLENTINO et al., 2016; VERIATO et al., 2018). A conservação do material a ser ensilado provém do ambiente, ausente em oxigênio e com reduzido $\mathrm{pH}(<4,0)$. Um ambiente anaeróbico é fundamental para prevenir o crescimento de microrganismos de deterioração aeróbia (incluindo fungos, leveduras e bactérias aeróbicas) pois muitos destes requerem oxigênio, já o baixo $\mathrm{pH}$ reduz a atividade de enzimas vegetais e inibe o crescimento de bactérias anaeróbias indesejáveis (MUCK; KUNG JR; COLLINS, 2020). O pH final de uma silagem resulta principalmente pela ação de bactérias anaeróbicas que fermentam carboidratos solúveis, presentes na cultura , produzindo ácido lático,

ácido acético, ácido propiônico, ácido butírico e outros compostos (MUCK, 1988; MUCK, Nucleus Animalium v.13, n.1, maio 2021 
KUNG JR; COLLINS, 2020). Bactérias produtoras de ácido lático (LAB) predominantes no processo são desejáveis, estas fermentam principalmente glicose para produção de ácido (BORREANI et al., 2018). Quando o substrato não é limitante, LAB dominam o processo fermentativo, produzindo ácido lático que acidifica o meio até que um $\mathrm{pH}$ seja atingido que suprime o crescimento destas próprias, resultando assim em uma silagem estável (ROOKE; HATFIELD, 2003).

O processo de produção de silagem é normalmente dividido na fase aeróbia após a colheita, fase de fermentação anaeróbica, fase estável de armazenamento no silo e fase de alimentação em que a face do silo está aberta e o material é exposto ao ar (BORREANI et al., 2018). Durante todas estas fases ocorrem perdas podendo ser intensificadas ou não, dependendo do manejo adotado perante o processamento da cultura. Quando as perdas se intensificam durante o processo de fermentação, o valor nutritivo da silagem pode ser comprometido.

Para um bom processo fermentativo ocorrer o momento de colheita da cultura é crucial, sendo o ideal culturas que apresentem de 30 a 35\% de matéria seca (KUNG JR et al., 2018). A obtenção de silagens de qualidade com menores teores de matéria seca também se torna possível com o conhecimento das características intrínsecas da cultura, utilizando de técnicas que minimizem problemas relacionados à alta umidade. Borreani et al. (2018) citam que a pré murcha deve ser implementada para a redução de umidade e concentração de carboidratos solúveis em gramíneas. Os autores também descrevem que culturas com elevado teor de matéria seca no momento da ensilagem $(>40 \%)$ não permitem a correta compactação, favorecendo a presença de ar entre as partículas que faz com que microrganismos aeróbicos venham a se desenvolver e consequentemente aumentar as perdas. Neste sentido, o equilíbrio próximo ao ótimo teor de matéria seca deve ser buscado a fim de se propiciar a produção de uma silagem que venha a apresentar um bom valor nutritivo.

O desempenho animal depende, dentre outros fatores, do valor nutricional do alimento. O resultado de um processo fermentativo adequado, que produz uma boa silagem, são produtos finais como, $\mathrm{pH}$, percentuais de ácido lático, acético, propiônico e butírico, nitrogênio amoniacal/ nitrogênio total $\left(\mathrm{NH}_{3} / \mathrm{N}\right)$, etanol, dentre outros (TABELA 1). 
Tabela 1. Concentrações sugeridas de produtos finais da fermentação de silagens

\begin{tabular}{|c|c|c|c|c|}
\hline Item & $\begin{array}{c}\text { Silagem de } \\
\text { Leguminosa } \\
(\mathrm{MS}<30-35 \%)\end{array}$ & $\begin{array}{l}\text { Silagem de } \\
\text { Capim } \\
\text { (MS 25-35\%) }\end{array}$ & $\begin{array}{c}\text { Silagem de } \\
\text { Milho } \\
\text { (MS 30-40\%) }\end{array}$ & $\begin{array}{l}\text { Grão Úmido } \\
\text { (MS 70-75\%) }\end{array}$ \\
\hline $\mathrm{pH}$ & $4,3-4,5$ & $4,3-4,7$ & $3,7-4,0$ & $4,0-4,5$ \\
\hline Ácido lático (\%) & $6-8$ & $6-10$ & $3-6$ & $0,5-2,0$ \\
\hline $\begin{array}{l}\text { Ácido acético } \\
(\%)\end{array}$ & $2-3$ & $1-3$ & $1-3$ & $<0,5$ \\
\hline $\begin{array}{l}\text { Ácido } \\
\text { propiônico (\%) }\end{array}$ & $<0,5$ & $<0,1$ & $<0,1$ & $<0,1$ \\
\hline $\begin{array}{l}\text { Ácido butírico } \\
(\%)\end{array}$ & $<0,5$ & $<0,5-1,0$ & 0 & 0 \\
\hline Etanol (\%) & $0,5-1,0$ & $0,5-1,0$ & $1-3$ & $0,2-2,0$ \\
\hline $\mathrm{NH}_{3}-\mathrm{N}(\%)$ & $10-15$ & 10 & $5-7$ & $<10$ \\
\hline
\end{tabular}

Fonte: Adaptado de Kung JR et al. (2018).

\section{SILAGEM DE SORGO}

O sorgo (Sorghum bicolor L. Moench) é uma alternativa aplicável nos mais diversos sistemas brasileiros. Originária da África essa cultura tem a capacidade de adaptação e produz em condições desfavoráveis comparado com a maioria dos outros cereais, sendo seu cultivo mais recomendável em regiões com alguma carência hídrica. Em 2020 foram cultivadas mais de 877 mil hectares de sorgo em todo território brasileiro (SEAPA, 2021).

A produção de silagem de sorgo coincide com a utilização de menos recursos tecnológicos quando comparado à fenação de gramíneas (DANIEL et al., 2019). Os mecanismos adaptativos, seu alto rendimento de matéria seca e boa concentração de carboidratos solúveis (VERIATO et al., 2018), aliado às características fenotípicas que facilitam o plantio, manuseio, colheita e armazenamento (TOLENTINO et al., 2016) fazem com que a cultura do sorgo seja apta a ser conservada por ensilagem.

Dentre os pontos principais para o êxito no processo de ensilagem, a produtividade da cultura assume papel importante, visto que o procedimento gera gastos, devendo estes serem diluídos pela produtividade da lavoura. A produtividade varia em decorrência do genótipo utilizado (TABELA 2), conforme trabalhos de Araújo (2018) e Veriato et al. (2018), os quais 
avaliaram produções de diferentes genótipos experimentais pertencentes a Embrapa Milho e Sorgo, além de materiais já presentes no mercado, e observaram diferenças produtivas.

Tabela 2. Médias de produção de matéria verde e matéria seca em toneladas por hectare de diferentes genótipos de sorgo cultivados para produção de silagem de acordo com diferentes autores

$$
\text { Araújo (2018) Veriato et al. (2018) }
$$

\begin{tabular}{lccccc} 
& \multicolumn{5}{c}{ Genótipos } \\
\cline { 2 - 5 } & $12 \mathrm{~F} 02006$ & $12 \mathrm{~F} 03033$ & Volumax & 201191 & 201187025 \\
\cline { 2 - 5 } PMV $\left(\mathrm{t} \mathrm{ha}^{-1}\right)$ & 68,79 & 54,02 & 36,22 & 35,24 & 17,43 \\
PMS $\left(\mathrm{t} \mathrm{ha}^{-1}\right)$ & 20,70 & 16,58 & 9,41 & 12,37 & 6,48 \\
\hline
\end{tabular}

$\mathrm{PMV}=$ Produção de matéria verde por hectare; $\mathrm{PMS}=$ Produção de matéria seca por hectare.

Fonte: Adaptado de Araújo (2018) e Veriato et al. (2018).

O teor de matéria seca é um dos principais fatores responsáveis pela qualidade final da silagem. Valores ideais de pH $(3,8$ a 4,2) são encontrados em silagens com cerca de 30 a $35 \%$ de MS. Isso reflete na qualidade da silagem, pois o ácido lático responsável pela redução do $\mathrm{pH}$ estabiliza a silagem inibindo o crescimento de microrganismos deteriorantes (KUNG JR et al., 2018). Trabalhos já identificaram variações nos teores de matéria seca e pH (TABELA 3) entre tipos de genótipos de sorgo (COSTA et al., 2016; TOLENTINO et al., 2016; VERIATO et al.; 2018).

Tabela 3. Médias de matéria seca $(\%), \mathrm{pH}$ e relação nitrogênio amoniacal / nitrogênio total $\left(\mathrm{NH}_{3} / \mathrm{NT}\right)(\%)$ de genótipos de Sorgo cultivados para produção de silagem de acordo com diferentes autores

\begin{tabular}{lcccc}
\hline Genótipos & Matéria Seca & $\mathrm{pH}$ & $\mathrm{NH}_{3} / \mathrm{NT}$ & Autor \\
\hline 1016031 & 42,33 & 3,89 & 5,00 & \\
1016033 & 37,94 & 3,82 & 2,31 & Costa et al. \\
1016037 & 33,24 & 3,76 & 1,85 & $(2016)$ \\
1016039 & 30,14 & 3,74 & 1,47 & \\
Volumax & 26,37 & 3,67 & 1,82 & \\
\hline $12 \mathrm{~F} 38006$ & 44,46 & 4,11 & 2,44 & \\
$12 \mathrm{~F} 40006$ & 38,55 & 4,10 & 3,10 & Tolentino et al. \\
$12 \mathrm{~F} 40019$ & 38,01 & 3,94 & 3,52 & (2016) \\
$12 \mathrm{~F} 37016$ & 40,36 & 4,14 & 2,25 & \\
Volumax & 37,12 & 3,80 & 2,96 & \\
\hline
\end{tabular}


Tabela 3. Médias de matéria seca $(\%), \mathrm{pH}$ e relação nitrogênio amoniacal / nitrogênio total $\left(\mathrm{NH}_{3} / \mathrm{NT}\right)(\%)$ de genótipos de Sorgo cultivados para produção de silagem de acordo com diferentes autores.

(Conclusão)

\begin{tabular}{lcccc}
\hline Genótipos & Matéria Seca & $\mathrm{pH}$ & $\mathrm{NH}_{3} / \mathrm{NT}$ & Autor \\
\hline 201191 & 35,10 & 3,56 & 3,61 & \\
Santa Elisa & 32,54 & 3,57 & 2,66 & Veriato et al. \\
$2012 \mathrm{~F} 47523$ & 37,56 & 3,62 & 2,14 & (2018) \\
$2012 \mathrm{~F} 47524$ & 26,89 & 3,34 & 1,61 & \\
$2012 \mathrm{~F} 47525$ & 36,26 & 3,69 & 2,42 & \\
\hline
\end{tabular}

Fonte: Adaptado de Costa et al. (2016), Tolentino et al. (2016) e Veriato et al. (2018).

Em relação ao $\mathrm{NH}_{3} / \mathrm{NT}$, este deve ser inferior a $10 \%$ para que a silagem seja considerada de boa qualidade (COSTA et al., 2016). Nos resultados apresentados na Tabela 3 pode-se observar que todos os autores, independente do genótipo, observaram silagens com valores ideais para esse parâmetro. Maiores valores de $\mathrm{NH}_{3} / \mathrm{NT}$ são observados quando a fermentação é prejudicada resultando em perdas, principalmente por haver maior proteólise, sendo que tempos elevados para a redução do $\mathrm{pH}$ da silagem permitem que ocorram maiores fermentações butírica pela proliferação de bactérias do gênero Clostridium spp. (MUCK, 1988).

Outro aspecto nutricional que afeta diretamente no desempenho dos animais é a qualidade da fibra. A fibra pode ser definida como a fração lentamente degradável e/ou indegradável, que ocupa espaço no trato digestivo (OLIVEIRA et al., 2011). A caracterização da fração fibrosa do alimento permite melhor entendimento do seu aproveitamento pelo animal. A fibra em detergente neutro (FDN) e fibra em detergente ácido (FDA) são indicativos da qualidade da fibra. Valores acima de $60 \%$ de FDN podem vir a limitar o consumo dos animais (COSTA et al., 2016). Valores elevados (> 30\%) de FDA são indesejáveis, pois podem indicar a presença de constituintes lignocelulósicos, que se ligam aos carboidratos estruturais das forrageiras diminuindo assim a digestibilidade da fibra (SILVA et al., 2015).

Na Tabela 4 estão apresentados resultados de análises contendo médias de FDN e FDA encontrados por Costa et al. (2016) ao trabalharem com diferentes genótipos de sorgo. São verificadas diferenças em relação aos materiais utilizados, sendo observados valores elevados de FDN e FDA em relação ao recomendado para não afetar negativamente o consumo dos animais. Os autores justificaram os elevados valores em decorrência do fato de que as plantas passaram do ponto ideal de colheita, o que favoreceu o desenvolvimento da fração fibrosa e maior lignificação da parede celular das plantas. 
Tabela 4. Média de fibra em detergente neutro (FDN) e fibra em detergente ácido (FDA) da silagem de genótipos de sorgo cultivados para produção de silagem

\begin{tabular}{lcc}
\hline Genótipos & FDN (\%) & FDA (\%) \\
\hline 1016009 & 69,32 & 40,98 \\
1016011 & 67,27 & 52,28 \\
1016013 & 69,97 & 52,42 \\
1016017 & 65,28 & 52,95 \\
1016025 & 62,99 & 54,46 \\
1016029 & 72,12 & 54,69 \\
1016031 & 68,14 & 44,61 \\
1016033 & 64,33 & 38,92 \\
1016035 & 49,40 & 53,24 \\
1016037 & 69,13 & 47,21 \\
1016039 & 57,43 & 56,33 \\
BRS 655 & 66,34 & 44,85 \\
Volumax & 61,05 & 51,50 \\
BRS 610 & 55,85 & 43,70 \\
SF 15 & 44,64 & 53,03 \\
\hline
\end{tabular}

Fonte: Adaptado de Costa et al. (2016).

\section{UMA NOVA PERSPECTIVA: SILAGEM DE SORGO BIOMASSA NA ALIMENTAÇÃO} ANIMAL

Como já citado, forrageiras com alta produção por unidade de área e que apresentem bom valor nutritivo são buscadas para regiões semiáridas devido os desafios de produção de alimento para os ruminantes neste tipo de clima. Neste sentido, o sorgo forrageiro tem sua utilização difundida com uma razoável produção (10 à 20 t de matéria seca ha ${ }^{-1}$; ARAÚJO, 2018; VERIATO et al., 2018). Entretanto, a Empresa Brasileira de Pesquisa Agropecuária (EMBRAPA) vem lançando desde 2013 cultivares de sorgo biomassa que tem como principal intuito o fornecimento de biomassa para a produção energética (ALMEIDA et al., 2019; MAY, SILVA; SANTOS, 2013). As principais características deste tipo de sorgo são seu alto crescimento, com plantas atingindo altura de até 6 metros, além de elevada produtividade acima de 50 t de matéria seca ha ${ }^{-1}$, possuir tolerância a pragas e doenças, ao déficit hídrico, e resistência ao acamamento (ALMEIDA et al., 2019; CASTRO et al., 2015; SILVA et al., 2018).

Castro et al. (2015) ao avaliarem produção de matéria verde de diferentes híbridos de sorgo encontraram produções de até 120,8 t de matéria verde $\mathrm{ha}^{-1}$ para híbridos de sorgo biomassa, já o cultivar de sorgo forrageiro volumax alcançou apenas 56,5 t de matéria verde ha ${ }^{-1}$, demonstrando a superioridade em produção do sorgo biomassa em relação ao cultivar de sorgo forrageiro mais empregado para a produção de silagem.

Nada impede a utilização do sorgo biomassa na alimentação de ruminantes. As características desejáveis da fibra tanto para fins energéticos quanto nutricionais são semelhantes. 
A celulose e a hemicelulose sob hidrólise enzimática produzem açúcares fermentáveis para produção de biocombustíveis (CASTRO et al., 2015), já no rúmen este processo também ocorre fornecendo energia para os microrganismos.

Outra característica da fibra em comum para ambos os propósitos é a preferência por menores teores de lignina, pois esta afeta a digestibilidade da fibra para os ruminantes e altas porcentagens de lignina necessitam de maiores concentrações das enzimas para o processamento da biomassa, tornando este economicamente inviável (CASTRO et al., 2015; SILVA et al., 2018).

O sorgo biomassa tem seu potencial forrageiro evidenciado, pois, além de apresentar altas produções de matéria seca por hectare, permite a obtenção de silagens de bom valor nutritivo (TABELA 5). Caxito (2017) ao avaliar a qualidade nutricional de silagens de sorgo biomassa, sacarino e forrageiro, cultivado em condições de sequeiro na região semiárida de Minas Gerais, concluiu que os genótipos de sorgo biomassa (BRS 716 e CMSXS 7016) têm aptidão forrageira, pois não apresentaram diferenças na digestibilidade da matéria seca e obtiveram maior produção de matéria seca digestível em relação aos genótipos de sorgos sacarinos e forrageiros avaliados.

Tabela 5. Valores médios de matéria seca (MS), proteína bruta (PB), lignina (LIG), fibra em detergente neutro indigestível (FDNi) e pH de silagens de sorgo biomassa

\begin{tabular}{lccccc}
\hline & MS (\%) & PB (\%) & LIG (\%) & FDNi (\%) & pH \\
\hline BRS716 & 26,83 & 6,89 & 4,35 & 29,26 & 4,21 \\
CMSXS7016 & 25,13 & 7,67 & 3,80 & 31,40 & 4,46 \\
\hline
\end{tabular}

Fonte: Adaptado de Caxito (2017).

Em trabalho pioneiro, Ramos et al. (2021) avaliaram a substituição de silagem de sorgo forrageiro (SSF) cultivar volumax pela silagem de sorgo biomassa (SSB) cultivar BRS 716 em diferentes proporções na dieta $(0,50,75$ e 100\%) de vacas F1 Holandês X Zebu sobre sua ingestão e digestibilidade de nutrientes e a resposta para produção e composição do leite, além do custo das dietas, em Janaúba inserida no semiárido de Minas Gerais. Os autores verificaram que a substituição total (100\%) da SSF pela SSB não alterou a produção de leite e produção de leite corrigida para 3,5\% de gordura com média de $12,86 \mathrm{~kg} /$ dia e $13,42 \mathrm{~kg} /$ dia, respectivamente. A substituição de SSF por SSB reduziu o consumo de matéria seca em $0,02 \mathrm{~kg}$ para cada $1 \%$ de inclusão de SSB, entretanto, não havendo diferença na ingestão de proteína bruta, fibra em detergente neutro, extrato etéreo e nutrientes digestíveis totais. Outro aspecto interessante foi de que a substituição completa da SSF por SSB reduziu o custo da dieta dos animais em $28,8 \%$. 
Deste modo foi concluído a SSF pode ser substituída em até $100 \%$ pela SSB na dieta de vacas F1 Holandês X Zebu em lactação.

Diante disto, futuros trabalhos podem vir a consolidar o potencial forrageiro de cultivares de sorgo biomassa na alimentação de ruminantes. Aproveitando de sua alta produção por área, que vem a permitir otimizar a produção forrageira em épocas propicias ao cultivo, algo limitado nos casos de regiões semiáridas, assim, auxiliando a produção animal em sistemas submetidos a este tipo de condições climáticas.

\section{SILAGEM DE BRS CAPIAÇU}

O capim-elefante (Pennisetum purpureum Schum) se destaca entre as espécies forrageiras tropicais, devido seu alto potencial de produção de matéria seca, com boa qualidade da forragem e aceitabilidade pelos animais (PEREIRA; LÉDO; MACHADO, 2017). A Embrapa Gado de Leite através do programa de melhoramento do capim elefante lançou recentemente o BRS Capiaçu, tendo sido registrado no Ministério da Agricultura Pecuária e Abastecimento em 2015 (PEREIRA, et al., 2016).

O BRS Capiaçu se distingue dos demais cultivares de capim-elefante devido seu maior rendimento (TABELA 6) e qualidade da forragem (PEREIRA; LÉDO; MACHADO, 2017), além de seu objetivo de utilização ser na forma do capim verde picado, ou para confecção de silagem (PEREIRA, et al., 2016). Dentre as características forrageiras do BRS Capiacu os mesmos autores destacam a resistência ao tombamento, facilidade para a colheita mecânica, ausência de pilosidade (pelos) e touceiras eretas e densas. Resultados demonstraram que o BRS Capiaçu produziu 26,1\% a mais de matéria seca por hectare ao ano que o cultivar Mineiro, e 40,0\% a mais em relação ao cultivar Cameron (PEREIRA; LÉDO; MACHADO, 2017). Pereira et al. (2016) ressaltam que o potencial de produção de biomassa do BRS Capiaçu atinge médias de 50 toneladas de matéria seca por hectare ao ano.

Tabela 6. Médias de produção total de matéria seca (PTMS) por ano ( $\left.\mathrm{t} \mathrm{ha}^{-1}\right)$ dos cultivares BRS Capiaçu, Mineiro e Cameron

\begin{tabular}{lc}
\hline Cultivares & PTMS (t ha-1) \\
\hline BRS Capiaçu & 49,8 \\
Mineiro & 36,8 \\
Cameron & 29,9 \\
\hline
\end{tabular}

Fonte: Adaptado de Pereira, Lédo e Machado (2017).

O BRS Capiaçu apresenta tolerância ao estresse hídrico (PEREIRA, et al., 2016), logo, com a utilização de técnicas que possibilitem esse cultivar manifestar seu máximo potencial de 
produção de matéria seca, como por exemplo irrigações estratégicas, torna-o apto a ser um importante recurso forrageiro nas regiões semiáridas (MONÇÃO et al., 2019b).

Devido ao fato de se tratar de um cultivar com pouco tempo de lançamento no mercado os estudos com silagem de BRS Capiaçu são limitados, mesmo sendo esse um dos objetivos de utilização desse cultivar (PEREIRA, et al., 2016; PEREIRA; LÉDO; MACHADO, 2017). Neste sentido a busca deve ser feita em função das características do cultivar em relação ao seu potencial de ensilagem, ou seja, as características produtivas e de sua composição químicobromatológica em diferentes idades de corte (LEAL et al., 2020; MONÇÃO et al., 2019a; MONÇÃO et al., 2019b), para assim se determinar o momento correto do corte que proporcione um material ensilado de boa qualidade.

Neste sentido, Monção et al. (2019a) avaliaram a produtividade, composição química e digestibilidade in vitro de nutrientes do BRS capiaçu manejado em cinco idades de rebrota (30, 60, 90, 120 e 150 dias) em Janaúba-MG, localizada em uma região de clima semiárido, durante o verão. O BRS capiaçu foi implantado em 2016. A precipitação média anual durante o experimento foi de $876 \mathrm{~mm}$ com temperatura média de $24^{\circ} \mathrm{C}$. Os autores verificaram o aumento de produção de matéria verde e produção de matéria seca de $1.280 \mathrm{~kg} \mathrm{ha}^{-1}$ e $382 \mathrm{~kg} \mathrm{ha}^{-1}$, respectivamente (TABELA 7) quando a idade de corte foi de 30 para 150 dias. Também foi observado um incremento de $0,109 \%$ no teor de matéria seca (MS), de 0,104\% da fibra em detergente neutro (FDN), 0,099\% de fibra em detergente ácido (FDA) e 0,025\% de lignina em função do aumento de um dia na idade de corte. Em contrapartida, houve uma redução diária de $0,022 \%$ no teor de nutrientes digestíveis totais, $0,196 \%$ na digestibilidade in vitro da MS, 0,057\% na digestibilidade in vitro da proteína bruta e $0,256 \%$ na digestibilidade in vitro da FDN. Desta forma, os autores recomendaram que para o cultivo do BRS capiaçu no norte de Minas Gerias o momento ideal da colheita seria entre 90 e 120 dias, pois se alia a alta produtividade com valor nutritivo. 
Tabela 7. Médias de altura (m), produção de MV (PMV) $\left(\mathrm{kg} \mathrm{ha}^{-1}\right)$, produção de MS (PMS) $(\mathrm{kg}$ ha $\left.^{-1}\right)$, matéria seca (MS) (\%), proteína bruta (PB) (\%), FDN (\%), FDA (\%), Lignina $(\%)$, NDT (\%), digestibilidade in vitro da matéria seca (DIVMS), digestibilidade in vitro da proteína bruta (DIVPB) e digestibilidade in vitro da FDN (DIVFDN) do BRS Capiaçu em função de diferentes idades de rebrota

\begin{tabular}{|c|c|c|c|c|c|}
\hline \multicolumn{6}{|c|}{ Monção et al. (2019a) } \\
\hline Idade (dia) & 30 & 60 & 90 & 120 & 150 \\
\hline Altura (m) & 1,03 & 1,93 & 3,43 & 4,50 & 4,98 \\
\hline PMV (kg ha $\left.{ }^{-1}\right)$ & 36077 & 63385 & 125077 & 145385 & 187154 \\
\hline $\operatorname{PMS}\left(\mathrm{kg} \mathrm{ha}^{-1}\right)$ & 4502 & 9282 & 23783 & 33291 & 49859 \\
\hline MS (\%) & 11,69 & 13,80 & 17,50 & 21,25 & 24,33 \\
\hline PB $(\%)$ & 12,32 & 10,64 & 7,72 & 8,74 & 7,71 \\
\hline FDN $(\%)$ & 61,28 & 65,55 & 69,73 & 75,02 & 72,25 \\
\hline FDA $(\%)$ & 38,77 & 42,11 & 45,17 & 52,94 & 48,27 \\
\hline Lignina (\%) & 5,02 & 6,11 & 6,99 & 8,30 & 7,77 \\
\hline $\operatorname{NDT}(\%)$ & 43,32 & 43,14 & 42,45 & 39,65 & 41,69 \\
\hline DIVMS (\%) & 67,76 & 64,95 & 50,48 & 47,17 & 47,23 \\
\hline DIVPB $(\%)$ & 64,48 & 63,85 & 61,06 & 59,71 & 58,00 \\
\hline DIFDN (\%) & 53,69 & 50,15 & 33,00 & 28,05 & 25,95 \\
\hline \multicolumn{6}{|c|}{ Monção et al. (2019b) } \\
\hline Altura (m) & 0,52 & 0,98 & 1,59 & 2,19 & --- \\
\hline PMV (kg ha $\left.{ }^{-1}\right)$ & 5815 & 23954 & 60308 & 103077 & --- \\
\hline $\operatorname{PMS}\left(\mathrm{kg} \mathrm{ha}^{-1}\right)$ & 760 & 3999 & 10798 & 22115 & --- \\
\hline MS (\%) & 13,02 & 16,81 & 17,99 & 21,16 & --- \\
\hline FDN (\%) & 55,33 & 63,18 & 66,43 & 68,41 & --- \\
\hline FDA $(\%)$ & 34,01 & 38,86 & 44,99 & 46,22 & --- \\
\hline Lignina (\%) & 2,13 & 2,76 & 3,70 & 5,58 & --- \\
\hline NDT (\%) & 46,23 & 44,81 & 43,44 & 43,54 & --- \\
\hline PB $(\%)$ & 15,07 & 11,31 & 8,18 & 6,45 & --- \\
\hline
\end{tabular}

Fonte: Adaptado de Monção et al. (2019a) e Monção et al. (2019b). 
Já Monção et al. (2019b) avaliaram a produtividade e composição química do BRS capiaçu manejado em quatro idades de rebrota (30, 60, 90 e 120 dias) no mesmo local que Monção et al. (2019a) porém durante o inverno. Os autores verificaram aumento da altura em $76,3 \%, 94,4 \%$ na produção de matéria verde, $96,6 \%$ na produção de matéria seca, $38,5 \%$ no teor de matéria seca, 19,1\% no teor de FDN, 26,4\% no teor de FDA e 61,8\% no teor de lignina quando a idade de corte foi de 30 para 120 dias. Já os teores de proteína bruta e NDT reduziram $57,2 \%$ e 5,8\% respectivamente (TABELA 7). Assim, os autores concluíram que o aumento da idade do BRS capiaçu aumentou a produção por unidade de área enquanto diminuiu o valor nutricional, deste modo, a colheita é recomendada em 90 dias de rebrota durante o inverno nesta região para que melhor se equilibre a produtividade com a qualidade.

Trabalhos como este são de suma importância para que se possa determinar o melhor momento de se ensilar a cultura. No geral podemos observar que o BRS capiaçu se caracteriza por apresentar baixos teores de matéria seca (MONÇÃO et al., 2019a,b; PEREIRA, et al., 2016; PEREIRA; LÉDO; MACHADO, 2017), o que pode vir a aumentar as perdas e prejudicar o processo fermentativo durante a ensilagem. Assim a utilização de aditivos com alto teor de matéria seca pode vir a melhorar a qualidade de silagens produzidas com BRS capiaçu. Neste sentido, Silva et al. (2019) avaliaram o efeito de níveis de inclusão de glicerina bruta $(0,1,5,10$, e $15 \%$ da matéria natural) sobre a silagem de BRS capiaçu na composição química e nos parâmetros de fermentação. A inclusão de glicerina bruta reduziu o pH (de 3,99 para 3,74) e as perdas de efluentes $(38,45$ para $28,55 \mathrm{~kg} / \mathrm{t})$ e aumentou em 30,5\% o teor de MS na silagem de BRS capiaçu. Desta forma os autores vieram a concluir que a inclusão de $15 \%$ de glicerina bruta na matéria natural da silagem de BRS capiaçu melhorou a composição bromatológica e o perfil de fermentação.

\section{SILAGEM DE PALMA FORRAGEIRA}

A palma, é dentre as espécies forrageiras é uma das que melhor se adequam nas condições climáticas impostas pelo semiárido (MARQUES et al., 2017), servindo como base alimentar dos rebanhos (FROTA et al., 2015). Sua adaptabilidade pode ser atribuída a características morfofisiológicas (MENDES et al, 2012) xeromórficas, como raízes bem desenvolvidas, predominantemente superficiais (MARQUES et al., 2017), com destaque para o metabolismo diferenciado CAM (Metabolismo Ácido das Crassuláceas) que permite a esta forrageira um maior aproveitamento da água, visto que, plantas com este diferencial, abrem seus

Nucleus Animalium v.13, n.1, maio 2021 
estômatos durante a noite, mantendo-os fechados durante o dia, o que reduz a perda de água pela evaporação estomática (FROTA et al., 2015).

No Brasil as espécies mais utilizadas são a Opuntia ficus-indica Mill e a Nopalea cochenillifera Salm-Dyck (ROCHA, 2012). Dentre as variedades mais cultivadas, destacam-se a Gigante, Redonda, Orelha de elefante (todas do gênero Opuntia) e a Miúda (gênero Nopalea) (FROTA et al., 2015).

Como todo alimento, quando fornecido unicamente não consegue suprir as necessidades nutricionais de ruminantes com base na sua composição bromatológica (TABELA 8), principalmente devido baixos teores de matéria seca, proteína e FDN. Entretanto, vários trabalhos demonstram o sucesso da utilização da palma forrageira associada a diferentes fontes de fibras (LIMA et al., 2012; MENDES et al., 2012; SILVA et al., 2017; BORGES et al., 2019), não comprometendo a digestibilidade dos nutrientes nem a produção animal, sendo que em alguns casos, até melhoram estes aspectos.

Tabela 8. Média dos teores de matéria seca (MS), matéria mineral (MM), proteína bruta (PB), extrato etéreo (EE), fibra em detergente neutro (FDN) e fibra em detergente ácido (FDA) de diferentes cultivares de palma forrageira de acordo alguns autores Lima et al. (2012)

\begin{tabular}{lccc}
\hline & & Cultivar & \\
\cline { 2 - 4 } Variável (\%) & Gigante & Redonda & Miúda \\
\hline MS & 9,10 & --- & --- \\
MM & 12,57 & --- & --- \\
PB & 4,92 & --- & --- \\
EE & 2,17 & --- & --- \\
FDN & 31,87 & --- & --- \\
FDA & 20,38 & --- & --- \\
\hline & Cavalcante $e t$ al. $(2014)$ & Miúda \\
\hline & & Cultivar & 7,76 \\
Variável (\%) & Gigante & Redonda & 17,53 \\
\hline MS & 6,37 & 6,07 & 4,31 \\
MM & 15,94 & 17,75 & 3,09 \\
PB & 5,42 & 5,21 & 32,81 \\
EE & 2,98 & 3,20 & 19,97 \\
FDN & 28,30 & 27,05 & 19,32 \\
FDA & 20,93 & & \\
\hline
\end{tabular}

Fonte: Adaptado de Lima et al. (2012) e Cavalcante et al. (2014). 
Lima et al. (2012) verificaram que a associação de $61 \%$ de palma forrageira (Opuntia ficus-indica Mill) na dieta de ovinos recebendo silagem e feno não alterou o consumo de matéria seca e energia nem o pH ruminal dos animais. Mendes et al. (2012) também não observam diferenças na ingestão de matéria seca de suplementações a base de palma forrageira ou silagem de milho em vacas de leite mestiças. Silva et al. (2017) ao avaliarem a aceitabilidade e valor nutricional de palma forrageira (Opuntia ficus-indica Mill) por novilhas Girolando em função de diferentes períodos de armazenamento, observaram que o período de armazenagem em galpão fechado não alterou a aceitabilidade pelos animais. Borges et al. (2019) avaliaram dietas a base de silagem de sorgo, capim-elefante cv. Roxo, silagem de sorgo com 50\% de inclusão de palma forrageira (Opuntia ficus-indica Mill) e capim-elefante cv. Roxo com 50\% de inclusão de palma forrageira com vacas F1 Holandês X Zebu, os autores verificaram que a dieta silagem de sorgo com $50 \%$ de inclusão de palma teve uma digestibilidade $12,65 \%$ maior que a dieta de capimelefante cv. Roxo.

Trabalhos como estes ressaltam os benefícios da inclusão de palma forrageira na dieta de animais ruminantes, entretanto, não se observa qual é o comportamento dessa forrageira quando ensilada. Evidentemente que a palma forrageira apresenta altos teores de umidade, cerca de $90 \%$ da matéria natural (ROCHA, 2012), e que a alta atividade de água pode vir a prejudicar a fermentação das silagens (COSTA et al., 2016; TOLENTINO et al., 2016; VERIATO et al. 2018).

Entretanto trabalhos recentes (PEREIRA, 2019) vêm demonstrando que apesar do baixo teor de matéria seca (por volta de $10 \%$ ) a palma forrageira pode ser ensilada e produzir silagem de qualidade (TABELA 9). A principal justificativa é que o alto teor de carboidratos solúveis fornece substrato que é facilmente fermentável pelas bactérias produtoras de ácido lático, reduzindo o $\mathrm{pH}$, inibindo assim o crescimento de microrganismos indesejáveis (PEREIRA, 2019). Outra característica é que a mucilagem, uma mistura de polissacarídeos constituída por arabinose, galctose, ramnose e ácidos galacturônicos, apresenta propriedades osmóticas de absorver fluídos presentes na massa ensilada (FELKAI-HADDACHE et al., 2016).

Nucleus Animalium v.13, n.1, maio 2021 
Tabela 9. Composição química (\%), concentrações de ácido lático (AL), ácido acético (AA), ácido propiônico (AP), ácido butírico $(\mathrm{AB})$, nitrogênio amoniacal $\left(\mathrm{NH}_{3} / \mathrm{NT}\right)$ de silagem de palma cv. Miúda

\begin{tabular}{lc}
\hline Composição Nutricional & $\%$ \\
\hline Matéria Seca & 19,46 \\
Matéria Mineral & 9,21 \\
Proteína Bruta & 6,72 \\
Extrato Etéreo & 5,77 \\
Fibra em Detergente Neutro & 11,45 \\
\hline Produtos da Fermentação & $\%$ \\
\hline AL & 6,48 \\
AA & 1,40 \\
AP & 0,01 \\
$\mathrm{AB}$ & $<0,01$ \\
$\mathrm{pH}$ & 4,07 \\
$\mathrm{NH}$ & 0,21 \\
\hline
\end{tabular}

Fonte: Adaptado de Pereira (2019).

Entretanto, para a obtenção de silagens de palma forrageira com perfil de fermentação adequado, alguns pontos devem ser levados em consideração, sendo os principais o tamanho de partícula e a manutenção da anaerobiose (MONÇÃO et al., 2020; KUNG JR et al., 2018; PEREIRA, 2019). Os cuidados em relação ao tamanho de partícula devem se concentrar em se evita a maceração dos cladódios para não se intensificar a liberação de água que fica ligada a mucilagem, assim partículas de $2-5 \mathrm{~cm}$ seriam recomendadas. A mucilagem representa cerca de $14 \%$ do peso seco do cladódio, contendo aproximadamente $30 \%$ de água presente no parênquima de reserva (VENTURA-AGUILAR et al., 2017). A manutenção da água ligada à mucilagem evita altas quantidades de água livre no processo de fermentação, o que pode ser prejudicial. Em relação à manutenção da anaerobiose, esta é importante para a proliferação de LAB, pois a palma forrageira possui concentrações elevadas de pentoses (xilose e arabinose) e hexoses (manose, glicose e galactose) (HABIBI et al., 2004). Assim, as LAB utilizam esses açúcares como substrato para produzir ácido láctico, resultando em silagens com adequado perfil fermentativo (CARVALHO et al., 2014; PEREIRA, 2019).

Levando em consideração as dificuldades práticas em nível de campo relacionadas à ensilagem da palma forrageira (principalmente a compactação para criar o ambiente livre de ar) a confecção de silagens mistas de palma forrageira e gramíneas vem se tornando uma opção interessante (BRITO et al., 2020; MONÇÃO et al., 2020). Essa técnica tem por princípio se 
beneficiar dos carboidratos solúveis presentes na palma junto do maior teor de matéria seca da gramínea selecionada, o que pode vir a minimizar erros na produção de silagem.

Neste sentido Brito et al. (2020) avaliaram a silagem de palma forrageira (Opuntia ficus indica Mill.) com adição (0\%, 25\%, 50\%, 75\% e 100\%) de gliricídia (Gliricidia sepium (Jacq.) Steud) no produção de silagens mistas (TABELA 10). Além de adequado perfil fermentativo, os autores observaram que as silagens apresentaram excelente perfil fermentativo e alta estabilidade aeróbica (acima de 70 horas). Concluindo assim, que todas as silagens testadas foram adequadas, entretanto, considerando a estabilidade aeróbia da silagem exclusiva de palma forrageira, a adição de pelo menos $25 \%$ de gliricídia é recomendada.

Tabela 10. Matéria seca (\%), concentrações de ácido lático (AL), ácido acético (AA), ácido propiônico (AP), ácido butírico (AB), nitrogênio amoniacal $\left(\mathrm{NH}_{3} / \mathrm{NT}\right)$ de silagens mistas de palma forrageira acrescida de gliricídia aos 60 dias de abertura

\begin{tabular}{lccccc}
\hline $\begin{array}{l}\text { Inclusão } \\
\text { gliricídia (\%) }\end{array}$ & 0 & 25 & 50 & 75 & 100 \\
\hline Matéria seca & 15,6 & 18,1 & 20,8 & 23,6 & 24,1 \\
$\mathrm{pH}$ & 3,8 & 3,9 & 4,1 & 4,2 & 5,2 \\
$\mathrm{AL}$ & 9,0 & 7,2 & 6,3 & 5,3 & 1,7 \\
$\mathrm{AA}$ & 1,9 & 1,9 & 1,3 & 1,2 & 1,4 \\
$\mathrm{AP}$ & 0,1 & 0,2 & 0,2 & 0,2 & 0,2 \\
$\mathrm{AB}$ & $\leq 0,01$ & $\leq 0,01$ & $\leq 0,01$ & $\leq 0,01$ & $\leq 0,01$ \\
$\mathrm{NH}_{3} / \mathrm{NT}$ & 2,9 & 2,5 & 3,1 & 4,1 & 2,9 \\
\hline
\end{tabular}

Fonte: Adaptado de Brito et al. (2020).

Diferentemente, Monção et al. (2020) avaliaram a ensilagem do BRS capiaçu associado a palma forrageira em níveis de inclusão $(0,5,10,15$ e $20 \%$ na matéria natural) e apesar de colhido com 150 dias, o tratamento controle (apenas BRS capiaçu) produziu silagem de qualidade, porém com baixos valores de digestibilidade in vitro tanto da matéria seca quanto da fibra em detergente neutro. Em relação à palma forrageira os autores concluíram que até 5\% melhores resultados foram alcançados, visto que, apesar de maiores inclusões aumentarem a digestibilidade in vitro da matéria seca e da fibra em detergente neutro, as perdas de matéria seca por efluentes e gases se tornam maiores. 


\section{CONSIDERAÇÕES FINAIS}

O Sorgo Biomassa, o BRS Capiaçu e a Palma Forrageira apresentam características que as fazem reais alternativas forrageiras para regiões semiáridas.

Pesquisas devem ser efetuadas para consolidar dados da qualidade da silagem dessas forrageiras e seu valor nutritivo e como influenciam na produtividade dos animais ruminantes.

\section{REFERÊNCIAS}

ALMEIDA, L.G.F.; et al. Composition and growth of sorghum biomass genotypes for ethanol production. Biomass and Bioenergy, v.122, n.3, p.343-348, 2019.

ARAÚJO, G. G. L. Os impactos das mudanças climáticas sobre os recursos hídricos e a produção animal em regiões semiáridas. Revista Brasileira de Geografia Física, v 8, n 4, p 598-609, 2015.

ARAÚJO, J.J.S. Características agronômicas e valor nutricional de genótipos de sorgo. Janaúba/MG. 2018. 40 p. Dissertação (Mestrado em Zootecnia) - Universidade Estadual de Montes Claros, 2018.

BORGES, L. D. A.; et al. Nutritional and productive parameters of Holstein/Zebu cows fed diets containing cactus pear. Asian-Australasian Journal of Animal Scienses, v. 32, n. 9, p. 1373 $1380,2019$.

BORREANI, G.; et al. Silage review: Factors affecting dry matter and quality losses in silages. Journal of Dairy Science, v. 101,n. 5, p. 3952-3979, 2018.

BRASIL. Ministério da integração nacional. Nova delimitação semiárido. Brasília, DF, 2017. $63 \mathrm{p}$.

BRITO, G.S.M.S.; et al. Mixed silages of cactus pear and gliricidia: chemical composition, fermentation characteristics, microbial population and aerobic stability. Scientific reports, v. 10, n. 6834, p.1-13, 2020.

CARVALHO, B. F.; et al. Microbiological and chemical profile of sugar cane silage fermentation inoculated with wild strains of lactic acid bacteria. Animal Feed Science and Technology, v. 195, n. 9, p.1-13. 2014.

CASTRO, F.M.R.; et al. Agronomic and Energetic Potential of Biomass Sorghum Genotypes. American Journal of Plant Sciences, v.6, n.11, p.1862-1873, 2015.

CAVALCANTE, L. A. D.; et al. Respostas de genótipos de palma forrageira a diferentes densidades de cultivo. Pesquisa Agropecuária Tropical, v. 44, n. 4, p. 424-433, 2014. 
CAXITO, A.M. Desempenho agronômico e qualidade nutricional de silagens de sorgo biomassa, sacarino e forrageiro em região semiárida. Janaúba/MG. 2017. 70 p. Dissertação (Mestrado em Produção Vegetal no Semiárido) - Universidade Estadual de Montes Claros, 2017.

CORREIA, R. C.; et al. A região semiárida brasileira, In: VOLTOLINI, T. V. (Ed). Produção de caprinos e ovinos no semiárido. Petrolina: Embrapa Semiárido, 2011. cap. 1, p. 21-48.

COSTA, R. F.; et al. Agronomic characteristics of sorghum genotypes and nutritional values of silage. Acta Scientiarum Animal Sciences, v. 38, n. 2, p. 127-133, 2016.

DANIEL, J. L. P.; et al. Production and utilization of silages in tropical areas with focus on Brazil. Grass and Forrage Science, v. 74, n. 2, p. 1-18, 2019.

FELKAI-HADDACHE, L.; et al. Microwave optimization of mucilage extraction from Opuntia ficus indica Cladodes. International Journal of Biological Macromolecules, v. 84, n. 3, p. 2430, 2016.

FROTA, M. N. L.; Palma forrageira na alimentação animal. Teresina, PI: Embrapa MeioNorte, 2015, p. 48 (Documentos 233).

HABIBI, Y.; et al. Características estruturais de polissacarídeos pécticos da pele de frutos de pêra espinhosa Opuntia ficus-indica. Carbohydrate Research, v. 339, n. 6, p. 1119-1127, 2004.

KUNG JR, L.; et al. Silage review: Interpretation of chemical, microbial, and organoleptic components of silages. Journal of Dairy Science, v. 101,n. 5, p. 4020-4033, 2018.

LEAL, D.B.; et al. Correlações entre as características produtivas e nutricionais do capim-BRS capiaçu manejado na região semiárida. Brazilian Journal of Develop, v.6, n.4, p.18951-18960, 2020.

LIMA, W. W.; et al. Consumo, digestibilidade e parâmetros ruminais em ovinos recebendo silagens e fenos em associação à palma forrageira. Revista Brasileira de Saúde e Produção Animal, v.13, n.2, p.444-456, 2012.

MACÊDO, A. J. S.; et al. Potencialidades e limitações de plantas forrageiras para ensilagem: Revisão. Revista Brasileira de Higiene e Sanidade Animal, v.13, n.2, p. 320-337, 2019.

MARQUES, O. F. C.; et al. Palma forrageira: cultivo e utilização na alimentação de bovinos. Caderno de Ciências Agrarias, v. 9, n. 1, p. 75-93, 2017.

MAY, A.; SILVA, D. D.; SANTOS, F. C. Cultivo do sorgo biomassa para a cogeração de energia elétrica. Sete Lagoas, MG: Embrapa Milho e Sorgo, 2013, 69 p, (Documentos 152). 
MENDES, A. M. P.; et al. Ingestive behavior of pastured crossbred dairy cows offered different supplement types. Tropical Animal Health and Production, v. 45, n. 1, p. 231-237, 2012.

MONÇÃO, F. P.; et al. Yield and nutritional value of BRS Capiaçu grass at different regrowth ages. Semina: Ciências Agrárias, v. 40, n. 5, p. 2045-2056, 2019 a.

MONÇÃO, F. P.; et al. Productivity and nutritional value of BRS capiaçu grass (Pennisetum purpureum) managed at four regrowth ages in a semiarid region. Tropical Animal Health and Production, v. 51, n. 6, p 1-7, 2019 b.

MONÇÃO, F.P.; et al. Nutritional value of BRS Capiaçu grass (Pennisetum purpureum) silage associated with Cactus Pear. Iranian Journal of Applied Animal Science, v.10, n.1, p.25-29, 2020.

MUCK, R. E. Factors Influencing Silage Quality and Their Implications for Management. Journal of Dairy Science, v. 71, n11, p2992-3002, 1988.

MUCK, R.E.; KUNG JR, L.; COLLINS, M. Silage production. In: MOORE, K.J.; COLLINS, M.; NELSON, C.J.; REDFEARN, D.D. (Organizadores). Forages: The Science of Grassland Agriculture. $7^{\mathrm{a}}$ ed. Wiley Online Library, 2020. Cap 42, p.767-787.

OLIVEIRA, A. S.; et al. Meta-análise do impacto da fibra em detergente neutro sobre o consumo, a digestibilidade e o desempenho de vacas leiteiras em lactação. Revista Brasileira de Zootecnia, v. 40, n. 7, p. 1587-1595, 2011.

PEREIRA, A. V.; et al. BRS Capiaçu: cultivar de capim-elefante de alto rendimento para produção de silagem. Juiz de Fora, MG: Embrapa Gado de Leite, 2016, p. 6 (Comunicado Técnico 79).

PEREIRA, A. V.; LÉDO, F. J. S.; MACHADO, J. C. BRS Kurumi and BRS Capiaçu - New elephant grass cultivars for grazing and cut-and-carry system. Crop Breeding and Applied Biotechnology, v.17, n.1, 2017.

PEREIRA, G. A. Prospecção e uso de culturas láticas como inoculantes na ensilagem de palma forrageira. 2019. 94 p. Tese (Doutorado em Zootecnia) - Universidade Federal da Paraíba, Areia - PB, 2019.

RAMOS, J.C.P.; et al. Effect of replacing forage sorghum silage with biomass sorghum silage in diets for F1 Holstein $\times$ Zebu lactating cows. Tropical Animal Health and Production, v.53, n.1, p.1-12, 2021.

ROCHA, J. E. S. Palma Forrageira no Nordeste do Brasil: Estado da Arte. Sobral, CE: Embrapa Caprinos e Ovinos, 2012, p. 40 (Documentos 106). 
ROOKE, J.A. HATFIELD, R.D. Biochemistry of Ensiling. In: BUXTON, D.R.; MUCK, R.E.; HARRISON, J.H. (Organizadores). Silage Science and Technology. $42^{\mathrm{a}}$ ed. American Society of Agronomy, 2003. Cap. 3, p. 31-93.

SAMPAIO, R. L.; et al. The nutritional interrelationship between the growing and finishing phases in crossbred cattle raised in a tropical system. Tropical Animal Health and Production, v. 49, n. 5, p. 1015-1024, 2017.

SANTOS, P. M.; et al. Mudanças climáticas globais e a pecuária: cenários futuros para o semiárido brasileiro. Revista Brasileira de Geografia Física, v 4, n 6, p 1176-1196, 2011.

SECRETARIA DE ESTADO DE AGRICULTURA, PECUÁRIA E ABASTECIMENTO DE MINAS GERAIS - SEAPA. Relatórios da Agricultura-Sorgo, 2021. Belo Horizonte. Brasil, 20 p.

SILVA, E. T. S.; et al. Acceptability by Girolando heifers and nutritional value of erect prickly pear stored for different periods. Pesquisa Agropecuária Brasileira, v. 52, n.9, p. 761-767, 2017.

SILVA, M. D. A.; et al. Avaliação da composição químico-bromatológica das silagens de forrageiras lenhosas do semiárido brasileiro. Semina: Ciências Agrárias, v. 36, n. 1, p. 571-578, 2015.

SILVA, M.C.A.; et al. The Effect of Graded Levels of Crude Glycerin in BRS Capiaçu Grass Silage: Fermentation Profile and Bromatological Composition. Iranian Journal of Applied Animal Science, v.9, n.4, p.597-602, 2019.

SILVA, M.J.; et al. Evaluation of the potential of lines and hybrids of biomass sorghum. Industrial Crops \& Products, v.125, n.12, p.379-385, 2018.

TOLENTINO, D. C.; et al. The quality of silage of different sorghum genotypes. Acta Scientiarum Animal Sciences, v. 38, n. 2, p. 143-149, 2016.

VENTURA-AGUILAR, R. I.; et al.; Cactus stem (Opuntia ficus-indica Mill): anatomy, physiology and chemical composition with emphasis on its biofunctional properties. Journal of the Science of Food and Agriculture, v. 97, n.15, p.5065-5073, 2017.

VERIATO, F. T.; et al. Fermentation characteristics and nutritive values of sorghum silages. Acta Scientiarum Animal Sciences, v. 40, [s.n.], p. 1-8, 2018. 
WILKINSON, J. M., RINNE, M. Highlights of progress in silage conservation and future perspectives. Grass and Forrage Science, v. 73, n. 1, p. 40-52, 2017. 